\section{Poetry tells us that our souls have a shadow: can science respond?}

Sir-Maurice Riordan's enjoyable, perceptive Words essay "The suspense of strangeness" (Nature 409, 457; 2001) provides much information and insight. I would like to add some comments on how scientific training, method and language can be valuable to a poet. The compacted prose of scientific writing is training for writing concise poetry - especially in formats such as haiku. The necessary sitting, thinking and composition required to write poems can be made easier by the strict disciplines of scientific training.

Riordan writes from a poetic standpoint rather than, as I do, from a poet-scientist perspective. The perception that poets - and the general public have of scientists is different from creative scientists' own perception of themselves. My definition of a poet is a person who has poems published after critical review by an independent publisher. Unfortunately, this produces the question: what is a poem? The Bristol Polygon poets in the United Kingdom would reply: "A poem is a poem when the person producing it says it is."

Some years ago, it was common in asthma conferences to schedule an afternoon to attempt to define asthma. The many discussions are crystallized by the comment "Asthma is like love: everyone knows what it is but no two people can agree the terms for its definition." Scientists know that the problem of definition is not confined to poetry or literature.

The answer to Riordan's provocative question "Why doesn't a scientific sense of wonder translate readily into poetry?" is that it can be and has been translated, but suffers the defects of all translocations and the inherent difficulty in writing good poetry. As a scientist, I appreciate that scientific discoveries and laws provide an imperfect insight into phenomena comparable to that partial vision provided by poetry. While scientists attempt to reveal or unveil the natural philosophy of the Universe, we should all be aware of how ineffectually we individually achieve that grand aim. Poets are often similarly ineffectual. Both groups have a literature which manifests their collective effectiveness.

Scientific poets may be more common than Riordan suggests: Alex Comfort, for example, published reputable poetry. And there's no bimodal separation into poets and non-poets: Siegfried Sassoon wrote that the night before his platoon went into action, during the First World War, a third of the men became poets. In science we are familiar with the transformation of indifferent starters to excellent $\mathrm{PhD}$ graduates. I know of no evidence that the ratio of scientist-poets to scientists is any different from that of non-scientific poets to the non-scientific population.

However, creative scientists rarely have formal literary training. Accordingly, they are less likely than their pure poetic counterparts to be knowledgeable about what other poets have written. The standard of English language in many scientific publications is not high, offering little encouragement or example. Society's image of poets, or indeed of scientists, could make a scientist wary of being known as a poet for fear of reducing his or her scientific credibility. I believe that scientist-poets emerge from the woodwork with maturity or when they know their reputation is established.

Why should a reputable scientist bother about poetry? Gregory Corso (in Penguin Modern Poets volume 5, Cox \& Wyman, London, 1963) explains:

"I love poetry because it makes me love and presents me life...

But it does tell me my soul has a shadow."

Scientists can be and are poets. They may provide language and perspectives that are interestingly different from the general populace of poets.

Fleming Carswell

Department of Pathology \& Microbiology, School of Medical Sciences, University Walk, University of Bristol, UK

\section{Call to work together on microarray data analysis}

Sir - Your Opinion article about gene expression, "Free and public expression" (Nature 410, 851; 2001), and the accompanying News Feature about DNA microarrays, "When the chips are down" (Nature 410, 860-861; 2001), reveal the tip of the iceberg.

Even larger problems loom ahead than the microarray data acquisition discussed in your articles. There is as yet no analytical standard to interpret the data. Traditional statistical algorithms are not sufficient for modelling functional genomics, and additional analytical problems abound, for example the issue of decoding the data structures that relate gene expression to gene function in complex biological systems.

We are undertaking a community-wide experiment to review state-of-the-art algorithms in microarray data analysis, to identify key research problems to be addressed. Last October, the Duke University Bioinformatics Shared
Resource initiated a critical assessment of microarray data- analysis techniques (CAMDA) which invited the whole scientific community to analyse the same standard data sets.

CAMDA is a functional-genomics successor to other community-wide experiments, such as GASP (http://www. fruitfly.org/GASP1) in genomics and CASP (http://predictioncenter.llnl.gov) in protein modelling.

CAMDA 2000 mobilized researchers in traditionally separate fields of study, creating an interactive forum for a review of microarray-analysis techniques. For the first time, molecular biologists, statisticians, mathematicians, computer scientists, engineers and physicists were all involved in looking at a problem whose ultimate solution will require their collaboration. The plan is to have a meeting every year to evaluate and stimulate academic research and commercial developments in microarray data analysis (see http://www. bioinformatics.duke.edu/camda).

Kimberly Johnson, Simon Lin

Duke Bioinformatics Shared Resource, Box 3958, Duke University Medical Center, 248 Hanes,

Durham, North Carolina 27710, USA

\section{Medical luminaries}

Sir - May I add the names of more intellectual luminaries, whose careers were centred on Breslau/Wroclaw, to the list offered by Min-Liang Wong ("Bright light of learning snuffed out in Breslau”, Nature 410, 865; 2001).

Ferdinand Julius Cohn (1828-1898), the prominent botanist and microbiologist, father of bacterial taxonomy, was born in Breslau and became a professor at the university there. Julius Friedrich Cohnheim (1839-1884), pioneer of experimental pathology and the outstanding pupil of Rudolf Virchow, was a professor of pathology at the University of Breslau, where he published his fundamental work on the role of leukocytes in inflammation.

The fates of Cohn and Cohnheim and the city of Breslau are linked to a major event in the history of biology: in 1876, it was at Cohn's world-famous Institute of Plant Physiology that Robert Koch demonstrated the infectivity of anthrax bacilli, witnessed by Cohnheim. The pioneering studies of Koch on anthrax were published in Contributions to the Biology of Plants, the journal founded by Cohn in Breslau, along with many other major papers in bacteriology.

Edgar Pick

Julius Friedrich Cohnheim-Minerva Centre of Phagocyte Research, Sackler School of Medicine, Tel Aviv University, Tel Aviv 69978, Israel 